\title{
Commentary on Neumann's "Phenomena, Poiēsis, and Performance Profiling: Temporal-Textual Emphasis and Creative Analysis in Turandot at the Metropolitan Opera"
}

\author{
DANIEL BAROLSKY[1] \\ Department of Music, Beloit College, Beloit, WI
}

\begin{abstract}
This commentary situates Neumann's research within the existing literature on musicological ontologies of the musical work as well as scholarship on the analysis of performance and recordings. The response focuses on the interdisciplinary strength of the author's method while offering a few caveats about the analytical tools used. Although Neumann ventures into an under-explored territory (i.e. the analysis of operatic voices), I urge the author not to isolate this analysis from other elements of performance, including both visual content and listening experience
\end{abstract}

Submitted 2017 August 1; accepted 2017 August 8.

KEYWORDS: analysis of recordings, musicological ontologies, operatic sound

THERE are existing concepts of the musical work (Goehr, 1994), as well as scholarship (Cook, 2013; Leech-Wilkinson, 2009; Taruskin, 1995) that have demonstrated how the perception of so-called musical works as fixed and largely text-based objects has: 1) limited modes of analysis; 2) ignored the very real creative contributions of performers and listeners; 3) prioritized certain kinds of styles, repertoires, practices, and musics over others; and 4) ahistorically disregarded both aesthetic and technological developments that greatly influenced current and past epistemologies and ontologies of "music". The first half of Joshua Neumann's "Review of Phenomena, Poiēsis, and Performance Profiling: Temporal-Textual Emphasis and Creative Analysis in Turandot at the Metropolitan Opera" is, in some ways, late to the game, as is his argument that we move beyond the definitions of a musical object that have dominated mid-20th century literature. And yet Neumann's approach does more than reinvent the wheel, and rather offers another way to challenge the outdated conceptions of the musical work that still pervade and dominate our musical disciplines (despite previous work). Indeed, this manuscript cleverly uses the concept of technee, similar to how Feruccio Busoni talks about ideas of "transcription" (Busoni, 1987), to demonstrate the overlap between a musical score and its realization, in contradistinction to the view that a performance is merely a reproduction or supplement. Moreover, Neumann extends this idea to explore the relationship between opera and technology (from Mark Schubin) and, more importantly, the history of Ricordi's grappling with the implications of recordings on legal (and economic) definitions of musical objects (i.e. commodities). Both of these brief histories into music and technology reinforce the critical idea that any conception or perception of music is ontologically connected to the nature of its medium, and both the technologies used to produce it and perceive it.

The second half of Neumann's essay extends the applications of technology to the analysis of opera, drawing upon techniques (developed and used by Craig Sapp and Nicholas Cook) that enable the analyst to isolate distinct interpretive qualities of individual performers within a larger interpretive history and framework. Much of the work within the UK's CHARM as well as in North American work on performance and analysis has focused on instrumental music (especially piano performances). Thus Neumann's essay is a welcome departure from this norm and a brave exploration of operatic sound, especially since the majority of work that deals with performances, within the world of opera scholarship, has focused on dramaturgy or performance practice. Close studies of individual singers and individual performances have been few and far between. Although the listener is somewhat absent from his essay, Neumann admirably incorporates the perspective of two singers (Andréa Gruber and Marcello Giordani), whose descriptions of their own interpretations are compared with the author's own analytic results. The balance of power still remains in the hands of the analyst, but this study demonstrates productive ways to 
challenge the traditional imbalance which, ultimately, silences or dismisses the intentions or views of performers in favor of an analyst's "authoritative" reading.

As Nicholas Cook (2012) and others have argued, however, the analysis of performance has certain limitations insofar as one text (the score) is often replaced with another (the recording and, in particular, the ways analysts represent the sonic experience visually). Although Neumann pushes us to reimagine the musical object by focusing on the operatic voice instead of the dots and squiggles on a page, he is still tied to a Platonic idea of the musical work's "thing-ness" (i.e. Puccini's Turandot), rather than thinking more holistically of opera (or music in general) as a social practice, process, or event (Small, 1998). The author's interpretations are drawn only from a combination of fixed texts (the recording, the visual representation of said recording, the score/libretto, and the performer's intentions), not the experience of listening to and/or watching the opera. More to the point, all too often scholars attribute meaning to minute details that scores or analyses reveal, but these meanings might not be perceived in real time by audiences, whether amateur or musically trained. The next logical step in Neumann's study is to bring this work into the realm of musical perception. The triangular graphs might reveal one interpretation and it may resonate with the singer's intentions. However, would an audience discern these details (whether pointed out or not)? How do listeners differently interpret the characters conveyed in these performances? How concerned are they, in fact, with the dramatic narrative Neumann interprets in such depth? Finally, are there other musical elements (e.g. ornamentation, changes to the quality of the voice, dynamic contrasts) that captivate the listener?

Most critically missing from Neumann's account (and notably, given how the historical overview of opera and technology ends with cinematic presentations of opera), is any attempt to integrate the visual element (which includes not only dramaturgical elements and the mise-en-scène but also singers, their bodies, and identities) with the sonic. The very presence of celebrity or known singers (e.g. someone like Maria Callas) shape how some audiences experienced opera through the lens of the performer, or, merely as an assertion of their upper-class status (Koestenbaum, 1993). In other words, for some, what's important is the singer and her voice, not necessarily the operatic drama or the text. The absence of the visual does not take away from Neumann's analysis (since many of us also experience opera only through records), but needs to be considered in the author's broader ontological explorations of musical works since the focus on operatic sound need not come at the expense of music's visual side, but rather together with it.

All modes of analysis have limitations. Just as Schenkerian or neo-Riemannian graphs represent some musical qualities better than others (and/or adequately capture the experience of listeners), so, too, do the author's triangular analyses. One should be wary of drawing too extensive a conclusion about interpretive meaning from the comparison of tempi alone. Where one performer might attempt to capture a character's emotional state through the modification of tempo, others might draw more on timbral shifts or bodily gesture to capture the same dramatic or emotional effect. Neumann's analytic/interpretive claims about Gruber and Giordani are given greater support with respect to the singers' intentions (specifically because of the author's interviews with them) than many other analyses, and he was wise not to extend his interpretive gloss to the other singers whose performances provide him with the basis for analytic comparison.

I remain wary of the effectiveness of the triangular analytic models. It is all too easy to read more into these graphs than what is actually perceivable. Moreover, I would question the value of creating new performance profiles or tracking stylistic norms through these analytic means alone. There are many historic, technological, and musical variables that would need to be brought into the equation for the conclusions to be convincing. Nevertheless, Neumann's approach models new modes of analysis that draw widely from a range of disciplines and areas. The essay's strength lies in its efficient integration of methods (analysis and ethnography), the combinations of histories (e.g. opera and technology), and the exploration of sonic elements within a musical genre that have been underrepresented within music analytical traditions. 


\section{ACKNOWLEDGEMENTS}

This article was copyedited by Scott Bannister and layout edited by Kelly Jakubowski.

\section{NOTES}

[1] Correspondence can be addressed to Daniel Barolsky at barolskd@beloit.edu.

\section{REFERENCES}

Busoni, F. (1987). The Essence of Music (R. Ley, Trans.). New York, NY: Dover Publications.

Cook, N. (2012). Introduction: Refocusing Theory. Music Theory Online, 18(1). Retrieved August 10, 2017 from http://mtosmt.org/issues/mto.12.18.1/mto.12.18.1.cook.html

Cook, N. (2013). Beyond the Score: Music as Performance. New York, NY: Oxford University Press.

Goehr, L. (1994). The Imaginary Museum of Musical Works: An Essay in the Philosophy of Music. New York, NY: Oxford University Press. https://doi.org/10.1093/0198235410.001.0001

Leech-Wilkinson, D. (2009). The Changing Sound of Music: Approaches to Studying Recorded Musical Performance. London: CHARM, 2009.

Koestenbaum, W. (1993). The Queen's Throat: Opera, Homosexuality, and the Mystery of Desire. New York, NY: Vintage Books.

Small, C. (1998). Musicking: The Meanings of Performance and Listening. Middleton, CT: Wesleyan University Press.

Taruskin, R. (1995). Text and Act: Essays on Music Performance. New York, NY: Oxford University Press. 